\title{
Genetic Characterization of a Bacterial Locus Involved in the Activity of the $N$ Function of Phage $\lambda$
}

\author{
DAVID I. FRIEDMAN AND L. S. BARON
}

\begin{abstract}
Department of Microbiology, Medical School, The University of Michigan, Ann Arbor, Michigan 48104, and Department of Bacterial Immunology, Division of Communicable Diseases and Immunology, Walter Reed Army Institute of Research, Washington, D.C. 20012
\end{abstract}

Accepted November 16, 1979

\begin{abstract}
We report the genetic mapping of a locus of the Escherichia coli chromosome involved in the expression of the $N$ gene function of phage $\lambda$. This phage specified function regulates the subsequent transcription of most of the $\lambda$ genome. The bacterial locus involved in $\mathrm{N}$ expression, called $n u s$ for $\mathrm{N} u$ tilization substance, maps between $a s p B$ at minute 62 and $\arg G$ at minute 61 of the $E$. coli chromosome.

Two different bacterial variants in which $\lambda \mathrm{N}$ function is not active have been used in mapping the nus locus, a mutant of $E$. coli K12, Nus, and a hybrid bacterium formed by genetic transfer between $E$. coli and $S$. typhosa. Although these two bacterial variants exhibit slightly different phenotypes, chromosome transfer studies demonstrate that the same genetic region is involved in the observed $\mathbf{N}$-ineffective phenotype.

Dominance studies show that in the case of the Nus mutant, the us $^{+}$allele is dominant. This suggests that the nus ${ }^{+}$allele is responsible for the expression of a function necessary for $N$ product activity. In the case of transfer of the nus region from a Nus mutant to an $E$. coli-S. typhosa hybrid, the resulting hybrid assumes the phenotype of the Nus mutant. Genetic studies using P1 transduction demonstrate that the same genetic region is involved in the $\mathrm{N}$-ineffective phenotype of the two bacterial variants.
\end{abstract}

\section{INTRODUCTION}

The $\mathrm{N}$ gene of coliphage $\lambda$ specifies a protein which regulates the expression of most other $\lambda$ functions (Echols, 1971). This regulation occurs at the level of transcription, since in the absence of $\mathrm{N}$ function, transscription of the $\lambda$ genome is significantly reduced (Skalka et al., 1967; Kumar et al., 1969; Kourilsky et al., 1968). Two classes of bacterial strains have been isolated and found to limit $\lambda$ growth by inhibiting the action of the $\mathrm{N}$ protein. This has led to the conclusion that a host factor is necessary for this protein to be functionally active. One class is made up of mutant bacteria derived from strains of Escherichia coli which normally permit $\lambda$ growth (Pironio and Ghysen, 1970; Georgopoulos, 1971a; Friedman, 1971; Friedman et al., 1973a). A second class is made up of hybrid bacteria constructed by mating $E$. coli $\mathrm{K} 12$ donors with Salmonella recipients (Baron et al., 1970, 1972). In this study, we report the genetic characterization of a representative of each class; K95, an $E$. coli nus-mutant and WR4255, an $E$. coli-S. typhosa hybrid.

Although the Nus mutant, K95, and $S$. typhosa hybrid, WR4255, were obtained in uniquely different ways, both bacterial strains share the same major phenotypic characteristics; each bacterial type does not permit the growth of $\mathrm{N}$-dependent $\lambda$, but does permit the growth of $\mathrm{N}$-independent or partially $\mathrm{N}$-independent $\lambda$. The complete inhibitory effect of the Nus mutant, however, is conditional, being expressed only at high temperature, $42^{\circ}$, while the inhibitory effect of WR4255 is observable at all temperatures. A further difference is the fact that $\mathrm{N}$ function is partially active in the Nus mutant, 
whereas there is no evidence that $\mathrm{N}$ function is active, to any extent, in WR4255. Consistent with these inferences is the observation that one class of mutant phage selected for ability to grow in the Nus mutant at $42^{\circ}$ carries mutations mapping in the $\mathrm{N}$ gene and does not grow in WR4255 (Mural and Friedman, in preparation). The isolation of this class of phage mutants also shows that $\mathrm{N}$ protein can be synthesized in the Nus mutant at the restrictive temperature. In addition, studies in other laboratories (N. Franklin; S. Hu and W. Szybalski; personal communications) demonstrate that the $\mathrm{N}$ gene is transcribed normally in the Nus mutant under conditions where $\mathrm{N}$ function is not expressed. We therefore conclude that in the case of Nus, the mutation involved inhibits $\mathrm{N}$ expression at the level of $\mathrm{N}$ action and not at the level of $\mathrm{N}$ synthesis.

Previous studies have shown that the introduction of an additional $E$. coli chromosomal segment into hybrid WR4255 enabled this strain to produce $\lambda$ suggesting the presence of a $\lambda$ replication ( $\lambda r e p$ ) locus in this segment (Baron et al., 1972). We now report that the nus mutation maps in precisely the same genetic region which on transfer renders WR4255 able to plate $\lambda$. Further, these studies show that the Nus ${ }^{+}$phenotype is dominant when both the $n u s^{+}$and $n u s^{-}$alleles are present.

\section{MATERIALS AND METHODS}

Bacteria. The characteristics of the bacterial strains employed in this study are listed in Table 1.

Bacteriophages. Preparation of phage lysates and other phage procedures were as previously described (Baron et al., 1970; Friedman et al., 1973). Lysates of Plvir were obtained by the confluent lysis procedure (Adams, 1959). $\lambda c 190 c 17$ (the $c 17$ mutation permits constitutive $\mathrm{N}$-independent transcription of genes $c \mathrm{II}-0-\mathrm{P}), \lambda c \mathrm{I} 857$, and $\lambda^{++}$ were supplied by M. E. Gottesman. Plvir was supplied by J. L. Rosner. $\lambda c \mathrm{I} 857$ byp constructed in these laboratories is a partially $\mathrm{N}$-independent phage. The byp mutation (Hopkins, 1970; Butler and Echols, 1970) frees $Q$ expression from $N$ control; the $Q$ gene product, in turn, stimulates transcription of late $\lambda$ functions. $\lambda \mathrm{sx}$, an $\mathrm{N}$ independent phage selected for its ability to plate on the $S$. typhosa hybrid bacterium WR4255, carries a number of mutations, one mapping in the region of the $\lambda$ genome where the byp mutation is located (Baron et al., 1970).

Media. The media utilized have all pre-

TABLE 1

Characteristics of Strains ${ }^{a}$

\begin{tabular}{|c|c|c|c|}
\hline Strain & Description & Pertinent markers & Source or derivation \\
\hline WR2010 & E. coli K12 Hfr & O-tna $a^{+}-x y l^{+}-\operatorname{mal} A^{+} \ldots$ & E. A. Adelberg, AB313 \\
\hline WR2020 & E. coli $\mathrm{K} 12 \mathrm{Hfr}$ & O-arg $G^{+}-m a l A^{+}-x y l^{+} \ldots$ & E. A. Adelberg, AB312 \\
\hline WR2029 & E. coli K12 F'141 & F-malA ${ }^{+}-a s p B^{+}-a r g G^{+}$ & K. B. Low, KLF-41 \\
\hline WR2030 & $\begin{array}{l}E \text {. coli } \mathrm{K} 12 \mathrm{~F}^{\prime} \text { internal } \\
\text { deletion of } \mathrm{F}^{\prime} 140\end{array}$ & F-pyrE $E^{+}-x y l^{+}-a s p B^{+}-a r g G^{+}$ & Baron et al. (1972) \\
\hline WR2033 & E. coli K12 Hfr & $0-\arg G^{-}-m a l A^{+}-x y l^{+} \ldots$ & W. Maas, Ma 1065 (AB312 type Hfr) \\
\hline WR2034 & E. coli K12 Hfr & O- $a r g G^{+}-n u s^{-}-x y l^{+} \ldots$ & $\begin{array}{l}\text { Cotransduction of } \arg G^{+}-n u s^{-} \text {from } \\
\text { K206 to WR2034 with Plvir }\end{array}$ \\
\hline WR3050 & E. coli $\mathrm{K} 12 \mathrm{~F}^{-}$ & nus ${ }^{+}$ & E. A. Adelberg, AB1133 \\
\hline K95 & E. coli $\mathrm{K} 12$ & $n u s^{-}$ & Friedman (1971) \\
\hline $\mathrm{K} 206$ & E. coli $\mathrm{K} 12 \mathrm{~F}^{-}$ & $n u s^{-}$ & WR3050 \\
\hline WR2045 & E. coli K12 F- & $\arg G^{-} n u s^{+} \operatorname{asp} B^{-}$ & N. Glansdorff \\
\hline WR4255 & S. typhosa hybrid & $x y l^{-} \lambda r e p^{-}$ & Baron et al. (1972) \\
\hline WR4021 & S. typhimurium $\mathrm{Hfr}$ & $\mathrm{O}-i l v^{+}-x y l^{+}-a r g G^{+} \ldots$ & K. Sanderson, Hfr K-10 \\
\hline
\end{tabular}

a Abbreviations: arg, arginine; $i l v$, isoleucine and valine; asp, aspartic acid; mal, maltose; st $;$, streptomycin; $x y l$, xylose; nus, $N$ utilization substance; $\lambda r e p$, replication of $\lambda$; pyr, pyrimidine; + , utilized or present; -, not utilized or absent. 
viously been described in detail (Baron et al., 1970; Friedman et al., 1973a). Bacterial hybrids were initially selected and purified on appropriate minimal media, as were transductants. The selective techniques for obtaining particular hybrids depend on differences in nutritional requirements and/or resistance to streptomycin $(500 \mu \mathrm{g} / \mathrm{ml})$ between donor and recipient strains. Instability of hybrid strains for fermentation markers as an indication of diploidy was tested on MacConkey agar base (Difco or $\mathrm{BBL}$ ) containing $1 \%$ of the appropriate carbohydrate.

Identification of Nus Phenotype. The Nus phenotype can be identified by its effect on $\lambda$ growth in either of two ways (Friedman, 1971). Bacteria carrying the nus mutation inhibit $\lambda$ growth at $42^{\circ}$, but not at $32^{\circ}$ and inhibit the growth of $\lambda$ carrying the $c 17$ mutation at all temperatures. Thus, $\lambda$ will form plaques on a "lawn" of the Nus mutant at $32^{\circ}$, but not at $42^{\circ}$. On the other hand, $\lambda c 17$ (or $\lambda c \mathrm{I} c 17$ ) will not form plaques on a "lawn" of the Nus mutant at any temperature.

Transduction. Standard method for P1 transduction was used (Lennox, 1955).

\section{RESULTS}

\section{Genetic Mapping Using Hfr Donors}

In a previous study using Hfr donors, it was demonstrated that in the $S$. typhosa hybrid bacterium, WR4255, a region of the $E$. coli genome located between minutes 60 and 73 must be present in order for the $\mathrm{N}$ gene product of $\lambda$ to be functional (Baron et al., 1972). In these experiments, two $E$. coli $\mathrm{Hfr}$ strains were used which transfer the region of the $E$. coli chromosome between minutes 60 and 73 from opposite directions (see Fig. 1); WR2010 which transfers genetic markers in a counterclockwise direction originating at minute 73 and WR2020 which transfers genetic markers in the opposite direction originating at minute 60 . Each transfers the information necessary for $\lambda$ viability (activity of the $\mathrm{N}$ gene product) to $S$. typhosa hybrid WR4255 as an early marker. The $E$. coli locus involved was referred to as $\lambda$ rep.

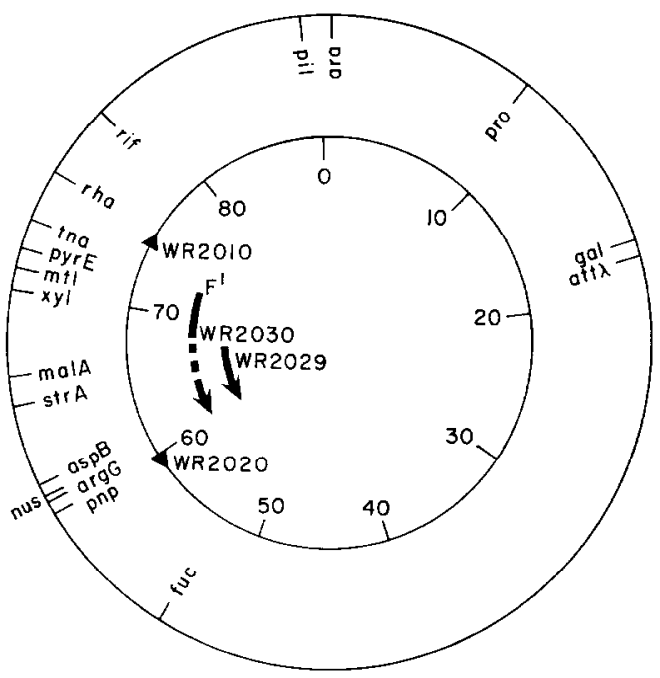

Fig. 1. Chromosome map of Escherichia coli K12. Included are the locations of pertinent genes and origins and directions of transfer of donor strains employed (Taylor and Trotter 1972).

Using these two Hfr donors in mating experiments with a Nus recipient, we have found that the Nus ${ }^{+}$phenotype (ability to support $\lambda$ growth at $42^{\circ}$ ) is transferred early by both Hfr strains. Therefore, it is concluded that the nus gene is located between minutes 60 and 73 of the $E$. coli chromosal map.

\section{Genetic Mapping Using Episomes}

The genetic information necessary for WR4255 to support $\lambda$ growth can be supplied by an $\mathrm{F}^{\prime}$ strain derived from $\mathrm{F}^{\prime} 140$ (Baron et al., 1972). The derivative $\mathrm{F}^{\prime}$ in WR2030 was thought to contain a region extending from minutes 66 to 72 since it was shown to carry the pyrE-mtl-xyl segment of $\mathrm{F}^{\prime} 140$, and was found to be deleted for the malA-strA region also carried by $F^{\prime} 140$. In light of these observations, it was suggested by Baron and his co-workers (1972) that the region of the $E$. coli genome needed to permit WR4255 to plate $\lambda$ locates between minutes 66 and 72 .

In order to perform analogous experiments with the Nus mutant, we constructed a nus derivative, K206, which carries a $x y l$ marker. The $F^{\prime}$ carried by WR2030, was transfcrred to this $\mathrm{Xyl}^{-}$recipient and $\mathrm{Xyl}^{+}$ exconjugants were obtained using streptomycin to select against the $s t r^{8}$ donor. The 
$\mathrm{Xyl}^{+}$exconjugants became $\mathrm{Nus}^{+}$as indicated by the observation that they would now plate $\lambda$ at $42 \mathrm{C}$. Therefore, we conclude that as in the case of WR4255, the Nus mutant is able to plate $\lambda$ under normally inhibitory conditions if the genetic region covered by the $\mathrm{F}^{\prime}$ of WR2030 is introduced into the bacterium.

However, experiments with another $\mathbf{F}^{\prime}$ containing-strain, WR2029, obtained as KLF41 (Low, 1968), suggested that the nus locus was not located in the minutes 66-72 region of the $E$. coli chromosome. Transfer experiments using the $\mathrm{F}^{\prime}$ contained in WR2029, which includes the genetic region extending from malA (minute 66) through $\arg G$ (minute 61) (see Fig. 1), showed that this $\mathrm{F}^{\prime}$ also carries the nus ${ }^{+}$allele. In thesc experiments, a malA- derivative of the Nus mutant was used as a recipient in a mating with the WR2029 donor. Again, the donor was $s t r^{\mathrm{s}}$ and the recipient was $s t r^{\mathrm{r}}$, and $\mathrm{Mal}^{+}$ recipients were obtained by using streptomycin to select against the donor. Although only thirteen of eighteen $\mathrm{Mal}^{+}$recipients became Nus ${ }^{+}$, the fact that so many $\mathrm{Mal}^{+}$ recipients did carry the us $^{+}$allele indicated that the $\mathrm{F}^{\prime}$ of WR2029 carries the nus $^{+}$region. This suggests that either WR2029 contains genetic information extending into the minutes 66-72 region or that WR2030 carries additional genetic material beyond that reported by Baron et al. (1972).

Our present studies demonstrate that WR2030 does in fact carry additional genetic material. We have found that although the episome contained in WR2030 is deleted for the malA ...strA region, approximately minutes 64-66 (Baron et al., 1972), it carries genetic markers located on either side of this region. Thus, in addition to the $p y r E$. . .xyl region (minutes $(70-72)$, WR2030 transfers the $\arg G$ gene which is located at minute 61 of the $E$, coli chromosome. We therefore conclude that W R2030 resulted from an internal deletion of $F^{\prime} 140$ and that the region between minutes 60-65 contains the nus ${ }^{+}$allele.

\section{Dominance Patterns of $\mathrm{nus}^{+} /$nus $^{-}$Diploids}

Most of the $\mathrm{Xyl}^{+}$exconjugants isolated from the cross of the $\mathrm{Xyl}^{-}$Nus mutant with the WR2030 donor yielded $\mathrm{XYl}^{-}$segregants at a high frequency and therefore were diploid for the $x y l$ region. This region of diploidy also included the gene(s) controlling the Nus phenotype, since all $\mathrm{Xyl}^{-}$segregants simultaneously became Nus ${ }^{-}$.

The isolation of these $\mathrm{nus}^{+} /$nus $^{-}$merodiploids permitted us to determine the dominance patterns of the nus mutation. The Nus $^{+}$and Nus ${ }^{-}$phenotypes are easily distinguishable since at $42^{\circ} \lambda \mathrm{N}$-dependent phages grow in a Nus ${ }^{+}$host, but not in a Nus $^{-}$host (Friedman, 1971). Figure 2 depicts the results of single-step growth experiments at $42^{\circ}$ following induction of three hosts that carry the $\mathrm{N}$-dependent prophage, $\lambda c I 857$. These hosts were all derived from WR3050 and had the following genotypes: $n u s^{+}, n u s^{+} / n u s^{-}$diploid, and $n u s^{-}$(derived

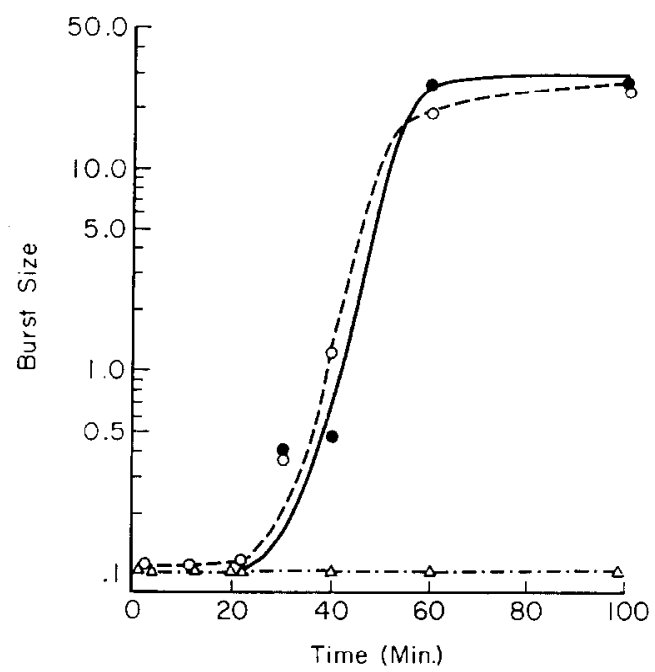

FIg. 2. Dominance of us $^{+}$allele. The following isogenic lysogens carrying the thermoinducible prophage, $\lambda c I 857$, were used to determine the dominance patterns of the nus mutation: K291, no episome/chromosome-nus ${ }^{+}$; K292, no episome/ chromosome-nus ; K290, episome-nus ${ }^{+} /$chromosome-nus-. Lysogens were grown until they reached "log-phase" growth conditions in M-9 medium containing $0.25 \%$ casamino acids with xylose as the carbon source. Lysogens were then induced by diluting cultures into $\mathrm{LB}$ broth which had been prewarmed to $42^{\circ}$. Cultures were maintained at $42^{\circ}$ and aliquots were removed at the indicated times, treated with chloroform, and plated on a sensitive lawn using tryptone top agar and tryptone plates. Plates were incubated overnight at $40^{\circ}$. Burst size was computed as the number of phage released per bacterium. $0---0$, $\mathrm{K} 291 ; \mathrm{K} 290 ; \triangle \cdot-\cdot-\triangle, \mathrm{K} 292$. 
as a $\mathrm{Xyl}^{-}$segregant from the $n u s^{+} / n u s^{-}$ diploid). As shown in Fig. 2, the growth of $\lambda c \mathrm{I} 857$ in the $n u s^{+}$and $n u s^{+} /$nus $^{-}$diploid strain was precisely the same. In comparison, there was no observable phage production following induction of the nus segregant which carried a $\lambda c \mathrm{I} 857$ prophage. We conclude that the $\mathrm{nus}^{+}$allele is dominant.

\section{Genetic Mapping by Transduction}

In order to map the location of the nus gene(s) more preciscly within the 60 to 65 minute region of the $\mathrm{K} 12$ chromosome, we used phage P1vir to transduce suitable markers in this region. $P 1$ lysates prepared on K206 $\left(\arg G^{+} n u s^{-} a s p B^{+}\right)$were used to infect WR2045 ( $\arg G^{-} n^{-} s^{+}$asp $B^{-}$) with subsequent selection being made for $\arg G^{+}$and $a s p B^{+}$as well as for double transductants $\left(\arg G^{+} a s p B^{+}\right)$. After purification, the transductants were screened for the presence of the Nus ${ }^{-}$trait as reflected by an inability to plate $\lambda c \mathbf{I} c 17$. The results listed in Table 2 indicate that the nus locus is very closely linked (approximately 90\% cotransduction) to the $\arg G$ gene at minute 61 of the $K 12$ chromosome. The results also show that the nus locus is $36 \%$ cotransducible with the asp $B$ marker near minute 62. The data in Table 2 as depicted in Fig. 3 also indicate that the nus locus maps between the $\arg G$ marker at minute 61 and the $a s p B$ marker

TABLE 2

MAPPING OF $a s p, n u s$, AND $\arg G$ by P1 Transduction

\begin{tabular}{|c|c|c|c|}
\hline Selected marker & Scored markers & \multicolumn{2}{|c|}{$\begin{array}{c}\% \text { Scored } \\
\text { markers }\end{array}$} \\
\hline$a s p^{+}$ & $\arg G^{-} n u s^{+}$ & $45)$ & \multirow{4}{*}{100} \\
\hline$a s p^{+}$ & $\arg G^{-} n u s^{-}$ & 19 & \\
\hline$a s p^{+}$ & $\arg G^{+} n u s^{+}$ & 2 & \\
\hline$a s p^{+}$ & $\arg G^{+} n u s^{-}$ & 34) & \\
\hline $\operatorname{nrg} G^{+}$ & $n u s^{+}$ & $10)$ & \multirow{2}{*}{100} \\
\hline $\arg G^{+}$ & $n u s^{-}$ & 90 & \\
\hline
\end{tabular}

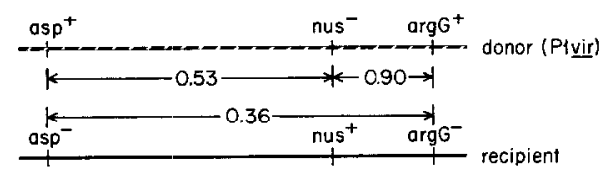

FIG. 3. Cotransduction frequencies of $a s p B$, nus, and $\arg G$. at minute 62 . These results are supported by the fact that all of 108 doubly $\left(\arg G^{+} a s p B^{+}\right)$ selected transductants obtained also had acquired the $n u s^{-}$trait.

\section{Dominance of nus in S. typhosa Hybrids}

Previously, it was shown that the ability to plate $\lambda$ was dominant in $S$. typhosa hybrids made diploid for the 60-72 minute region of the K12 chromosome (Baron et al., 1972). In order to directly compare the effects of the nus and rep loci wo detcrmincd if the nus trait, recessive to $n u s^{+}$in $E$. coli $\mathrm{K} 12$ merodiploids, is dominant in $S$. typhosa hybrids. Establishment of the precise location of the nus marker enabled us to construct a suitable Hfr strain for transfer of the nus allele to S. lyphosa hybrid WR4255. This was accomplished by cotransduction by Plvir of the closely linked $\arg G^{+}$nus ${ }^{-}$markers to an $\arg G^{-}$Hfr strain having the transfer orientation of WR2020. The resulting $\mathrm{Hfr}$ strain WR2034, which transfers its chromosome in the order $\mathrm{O}_{-} \arg \mathrm{G}^{+}{ }_{-} n u s^{-}-\mathrm{malA}^{+}-x y l^{+}$ ...metC $C^{+}-\mathrm{F}$, was then used for conjugal transfer of the chromosomal segment containing the nus locus to WR4255. In this cross, hybrids of WR4255 were selected on minimal xylose media using nutritional counterselection of the donor. Although occasional stable $\mathrm{Xyl}^{+}$hybrids were obtained, as in similar reported experiments (Baron et al., 1972), the $\mathrm{Xyl}^{+} \mathrm{WR} 4255$ hybrids isolated were predominantly unstable diploids yielding frequent $\mathrm{Xyl}^{-}$segregants. These merodiploids exhibit the Nus ${ }^{-}$phenotype in that they plate $\lambda$ and will not plate $\lambda c \mathrm{I} c 17$ at $32 \mathrm{C}$. In addition, $\mathrm{Xyl}^{-}$segregants lose the ability to plate $\lambda$ at all temperatures. From these results we infer that the $x y l^{+} / x y l^{-}$ WR4255 merodiploids also carry the nusmarker on the $\mathrm{K} 12$ diploid segment, and further that the nus and rep loci are either identical or closely linked.

\section{Transfer of גrep from Salmonella to E. coli}

The phenotypic similarity of the $\lambda r e p^{-}$ and $n u s^{-}$alleles as well as their close linkage suggested that these markers represent the same locus. We therefore used P1 transduction to map the $\lambda r e p^{-}$loci of Salmonella strains. Although it is possible to transduce some markers from $S$. typhosa hybrid 
WR4255 to $E$. coli $K 12$ recipients with P1vir, we were unable to recover any $\arg G^{+}$, transductants using an $\arg G^{-} E$. coli recipient. A less direct approach was therefore undertaken to map the location of the $\lambda r e p^{-}$ marker based on the assumption that $\lambda r e p$ may in fact be an equivalent locus to nus. This procedure involved transferring the $\arg ^{+}$region to an $E$. coli recipient by conjugation with an appropriate $S$. typhimurium Hfr strain. A cross was therefore performed between S. typhimurium Hfr WR4021 (transfer orientation $\mathrm{O}-i l v^{+}-x y l^{+}-\arg G^{+} \ldots$ $m e t E \ldots$. F) and an $\arg G^{-} E$. coli recipient with selection for $\arg G^{+}$recombinants. The small number of $\arg G^{+}$hybrids which appeared were tested after purification for sensitivity to $\lambda, \lambda c \mathbf{I} c 17, \lambda s x$, and $\lambda b y p$. All these $\arg G^{+}$hybrids proved to be insensitive to $\lambda$ and $\lambda c \mathrm{I} c 17$, but were able to plate $\lambda s x$ and $\lambda b y p$ at $37^{\circ}$. This pattern is identical to that exhibited by Salmonella hybrid WR4255 and indicates that these exconjugants had acquired the Salmonella $\lambda r e p$ locus.

Transduction studies, using one such $\arg G^{+} \lambda r e p^{-} E$. coli exconjugant, demonstrated that like the nus allele, the $\lambda r e p$ allele cotransduces at a high frequency with the $\arg G$ locus. In these experiments, lysates of Plvir propagated in the arg $G^{+} \lambda r e p^{-}$ strain were used to transduce an $a s p B^{-}$ $n u s^{+} \arg G^{-}$recipient WR2045. Analysis of the resulting $\arg G^{+}$transductants revealed that $92 \%$ also carried the $\lambda r e p^{-}$marker derived from $S$. typhimurium. However, none of over $100 \mathrm{aspB^{+ }}$ transductants carried the $\lambda r e p$ locus nor were any double $\left(\operatorname{asp} B^{+} \arg G^{+}\right)$transductants recovered. Thus it was impossible for us to order the location of $\lambda r e p$ with respect to the asp $B$ and $\arg G$ loci. We assume that these latter results reflect the genetic inhomology apparent in transduction of genes between E. coli and Salmonella. Nevertheless, it appears likely on the basis of all of the accumulated data that $\lambda r e p$ and nus represent equivalent loci.

\section{DISCUSSION}

Previously reported experiments using bacterial variants which inhibit $\lambda$ growth have demonstrated that in order for the phage-specified $\mathrm{N}$ function to be active, a bacterial-specified function must be present. In the case of the usual host for $\lambda, E$. col $i$ $\mathrm{K} 12$, two mutations, gro $\mathrm{N}$ and ron, which affect $\mathrm{N}$ activity, map near the rif $^{\mathrm{r}}$ genetic locus, minute 79 of the $E$. coli chromosome (Georgopoulos, 1971a; Pironio and Ghysen, 1970). Mutations to rif $^{\mathrm{r}}$ are associated with changes in RNA polymerase (Wehrli et al., 1968). Since the $N$ gene product is involved in the transcriptional process, it is not surprising that functional and biochemical studies indicate that both the ron and groN mutations are located within structural genes for RNA polymerase (Georgopoulos, 1971b; Ghysen and Pironio, 1972).

In contrast to the studies on the groN and ron mutation, our studies with another mutant of $E$. coli K12, Nus, and an E. coliS. typhosa hybrid, WR4255, demonstrate that an allele mapping in a region of the $E$. coli chromosome distant from the rif locus also is involved in permitting $\mathrm{N}$ function to be active. This was shown by our observation that the ability to plate $\mathrm{N}$-dependent phages could be transferred to either the Nus mutant or to the WR4255 hybrid when the chromosomal region corresponding to minute 61 of the $E$. coli chromosome was introduced either by $\mathrm{P} 1$ transduction or by $\mathrm{F}^{\prime}$ episome transfer.

The isolation of various strains diploid for the nus region permitted us to answer two crucial questions regarding the nus mutation: First, does the nus mutation actually define a function needed for $\mathrm{N}$ activity? Second, is the same allele involved in rendering $\mathrm{N}$ function active in Nus and WR4255?

The first question was answered by our studies with $n u s^{+} / n u s^{-}$diploid strains. In such diploids, $\mathrm{N}$-dependent phage grow as well as they do in $\mathrm{nus}^{+}$strains. Thus, the $n u s^{-}$mutation does not result in the formation of an inhibitor of $\mathrm{N}$ activity, but rather must cause an undersupply of a substance needed for $\mathrm{N}$ utilization, a component which can be supplied by the $n u s^{+}$allele. We will therefore continue to refer to this allele as $n u s, N$ utilization substance.

As to the second question, the transduction studies made possible by the isolation of appropriate diploids demonstrate that the 
nus and $\lambda$ rep alleles cotransduce at the same frequency with the $\arg G$ locus, which locates at minute 61 of the $E$. coli $\mathrm{K} 12$ chromosome. In addition, functional studies with the E. coli-S. typhosa diploid formed by transfer of the $\arg G$ region from a nus donor demonstrated that the new diploid assumed the characteristics of the nus mutant. That is, the resulting merodiploid plates $\lambda$, but not $\lambda c I c 17$. In contrast, the original hybrid bacterium, WR4255, which does not carry the minute 61 region from $E$. coli, plates neither phage. Therefore, we conclude that the allele mapping near $\arg G$ which is involved in $\mathrm{N}$ utilization is identical in both the Nus mutant and the E. coli-S. typhosa hybrid WR4255.

Although the nalure of the interaction between the Nus function and the $\mathrm{N}$ protein is not known, we do know something about the nature of the specificity of this interaction. Previous studies have shown that in order to be active $\mathrm{N}$ products with different recognition specificities require the presence of the Nus function. Thus, in addition to $\lambda$, a hybrid phage, $21 h y 5$ (LiedkeKulke and Kaiser, 1967) does not grow in the nus mutant at $42^{\circ}$ (Friedman, 1971), nor does it grow in WR4255 (unpublished observation). This hybrid phage carries the immunity region of phage 21 and expresses the $21 \mathrm{~N}$ function, an $\mathrm{N}$ function whose specificity of action differs from that of $\lambda$ (Friedman et al., 1973b). This difference in specificity is shown by the observations that the $\mathrm{N}$ of $\lambda$ is not active in stimulating expression of the 21 genome (Friedman et al., $1973 \mathrm{~b}$ ), and the $N$ of 21 is not active in stimulating the expression of the $\lambda$ genome (Couturier and Dambly, 1970; Herskowitz and Signer, 1970). Since the expression of both 21 and $\lambda \mathrm{N}$ functions are interfered with equally in Nus and WR4255, we conclude that the Nus substance itself has no specificity for either $\mathrm{N}$ product or for DNA with either the immunity region of $\lambda$ or the immunity region of 21 . The observed specificity for $\mathrm{N}$ must be determined by the $\mathrm{N}$ function itself or by an N-nus complex.

Although the Nus function is essential for $\lambda$ growth, we have not been able to determine whether the nus mutation affects any host physiological processes. In unreported experiments by Friedman and Jolly it was found that the growth rate of the nus mutant under a wide variety of conditions did not vary from that of the $n u s^{+}$parent strain. In addition, in the case of an induced operon, the kinetics of induction of $\beta$-galactosidase in the two strains was precisely the same. It did not escape our attention that the $p n p$ gene is located near argG (Reiner, 1969). Since polynucleotide phosphorylase can, under some conditions, polymerize mononucleotides into polynucleotides (GrunbergManago, 1963), it seemed possible that $p n p$. might be nus. However, two separate studies suggest that this is not the case. First, polynucleotide phosphorylase actively appears to be normal in extracts of the Nus mutant (unreported observations) and second, the $p n p$ and nus alleles map on opposite sides of the $\arg G$ gene.

In conclusion, we report the mapping of a new gene nus, the product of which is involved in the utilization of the phage specified regulatory function, the $\mathrm{N}$ product.

\section{ACKNOWLEDGMENTS}

The studies at The University of Michigan were supported by Grants from the National Science Foundation (GB-29595 X1) and the National Institutes of Allergy and Infectious Diseases (1RO 1 A111459-01).

We wish to acknowledge helpful discussions with P. Gemski, Jr., R. Mural and G. Wilgus and the excellent technical assistance of $I$. Ryman and C. Life. We are indebted to W. Maas, N. Glansdorff, A. Reiner, E. Adelberg, K. Low, and K. Sanderson for bacterial strains and to J. L. Rosner and M. Gottesman for phage strains.

\section{REFERENCES}

AdAMS, M. H. (1959) "Bacteriophages." Wiley (Interscience), New York.

Baron, L. S., Penido, E., Ryman, I. R., and FALKow, S. (1970). Behavior of coliphage lambda in hybrids between Escherichia coli and Salmonella. J. Bacteriol. 102, 221-233.

Baron, L. S., Ryman, I. R., Johnson, E. M., and Grmski, P., JR. (1972). Iytic replication of coliphage lambda in Salmonella typhosa hybrids. J. Bacteriol. 110, 1022-1031.

Butler, B., and Echols, H. (1970). Regulation of bacteriophage $\lambda$ development by gene $N$ : Properties of a mutation that bypasses $\mathbf{N}$ control of late protein synthesis. Virology 40, 212-222.

Couturier, M., and Dambly, C. (1970). Activa- 
tion séquentielle des fonctions tardives chez les bactériophages témpérés. C.R.Acad. Sci. Ser. D 270, 428-430.

Echols, H. (1971). Regulation of lytic development. In "The Bacteriophage Lambda (A. D. Hershey, ed.), pp. 247-270. Cold Spring Harbor Laboratories, Cold Spring Harbor, Ncw York.

Friedman, D. (1971). A bacterial mutant affecting $\lambda$ development. In "The Bacteriophage Lambda" (A. D. Hershey, ed.), pp. 733-738. Cold Spring Harbor Laboratories, Cold Spring Harbor, New York.

Frimdman, D. I., Jolly, C. T., and Mural, R. J. (1973a). Interference with the expression of the $\mathrm{N}$ gene product of phage $\lambda$ in a mutant of $E s c h$ erichia coli. Virology 51, 216-226.

Friedman, D. I., Wilgus, G. S., and Mural, R. J. (1973b). Gene $N$ regulator function of phage $\lambda$ imm21: Evidence that a site of $\mathbb{N}$ action differs from a site of $\mathrm{N}$ recognition. J. Mol. Biol. in press.

Georgopoulos, C. (1971a). A bacterial mutation affecting $\mathrm{N}$ function. In "The Bacteriophage Lambda" (A. D. Hershey, ed.), pp. 639-645. Cold Spring Harbor Laboratories, Cold Spring Harbor, New York.

Georgopoulos, C. P. (1971b). Bacterial mutants in which the gene $\mathrm{N}$ function of bacteriophage lambda is blocked have an altered RNA polymerase. Proc. Nat. Acad. Sci. U.S. 68, 2977-2981.

Ghysen, A., and Pironio, M. (1972). Relationship between the $\mathrm{N}$ function of bacteriophage $\lambda$ and host RNA polymerase. J. Mol. Biol. 65, 259-272.

Grunberg-Manago, M. (1963). Polynucleotide phosphorylase. Progr. Nucl. Acid Res. 1, 93-129.

Herskowitz, I., and Srgner, E. R. (1970). Control of transcription from the $r$ strand of bacteriophage lambda. Cold Spring Harbor Symp. Quant. Biol. 35, 355-368.
Hopkins, N. (1970). Bypassing a positive regulator: Isolation of a $\lambda$ mutant that does not require $\mathrm{N}$ product to grow. Virology 40, 223-229.

Kourulsky, P., Marcaud, L., Sheldrick, P., Luzzati, D., and Gros, F. (1968). Studies on the messenger RNA of bacteriophage $\lambda$. I. Various spccies synthesized early after induction of the prophage. Proc. Nat. Acad. Sci. U.S. 61, 1013-1020.

Kumar, S., Bøvre, K., Guha, A., Hradecna, Z., Maher, V. M., and Szybalski, W. (1969). Orientation and control of transeription in $E$, coli phage $\lambda$. Nature London 221, 823-825.

LenNox, E. S. (1955). Transduction of linked genetic characters of the host by bacteriophage P1. Virology 1, 190-206.

LiedKe-Kulke, M., and Kaiser, A. D. (1967). Genetic control of prophage insertion specificity in bacteriophages $\lambda$ and 21. Virology 32, 465-474.

Low, B. (1968). Formation of merodiploids in matings with a class of $\mathrm{rec}^{-}$recipient strains of Escherichia coli K-12. Proc. Nat. Acad. Sci. U.S. 60, 160-167.

Pironio, M., and Ghysen, A. (1970). A bacterial mutation which affects recognition of the $\mathrm{N}$ gene product of bacteriophage $\lambda . M o l$. Gen. Genet. 108, 374-375.

ReINer, A. M. (1969). Isolation and mapping of polynucleotide phosphorylase mutants of Escherichia coli. J. Bacteriol. 97, 1431-1436.

Skalka, A., Butler, B., and Echols, H. (1967). Genetic control of transcription during development of phage ג. Proc. Nat. Acad. Sci. U.S. 58, 576-583.

TAYlor, A. L., and Trotter, C. D. (1972). Linkage map of Escherichia coli Kl2. Bacteriol. Rev. 36, 504-524.

Wharli, W., Knusel, F., Schmid, K., and StaeHELIN, M. (1968). Interaction of rifanycin with bacterial polymerase. Proc. Nat. Acad. Sci. U.S. $61,667-673$. 